\title{
Violência em jogo: um panorama sobre o Batalhão Especializado de Policiamento em Estádios e sua relação com as torcidas cariocas
}

\author{
Camila Souza Gomes ${ }^{1}$ \\ Raquel de Oliveira Sousa ${ }^{2}$ \\ Recebido em março de 2021 \\ Aceito em junho de 2021
}

\begin{abstract}
RESUMO
O presente artigo deriva de duas etnografias realizadas junto ao Batalhão Especializado de Policiamento em Estádios (BEPE). A primeira, realizada entre 2016 e 2017, quando o batalhão ainda era chamado de Grupamento Especial de Policiamento em Estádios e a segunda se deu de abril a dezembro de 2019, já enquanto batalhão. Juntando nossos estudos e experiências, temos como objetivo descrever o policiamento em estádios no Rio de Janeiro e sua história; trazendo toda a trajetória deste batalhão e suas peculiaridades. No decorrer da pesquisa nos deparamos com a relação dos policiais militares com as torcidas, seus modos de controlá-las e divergências entre discurso e prática que norteavam as ações do batalhão; neste artigo também são exploradas algumas temáticas acerca das torcidas organizadas, suas práticas, as tensões da relação entre o BEPE e as torcidas cariocas e como é estabelecida a administração de conflitos neste ambiente repleto de emoções.
\end{abstract}

Palavras-chaves: Policiamento; Estádios; Administração de Conflitos.

\section{Violence in game: an overview of the specialized police battalion in stadiums and its relationship with the soccer fans from rio}

\begin{abstract}
This article comes from two ethnography with the "Specialized Police Battalion in Stadium". The first, held between 2016 and 2017, when the battalion was still called the "Special Policing Group in Stadiums", and the second one was held from April to December 2019, while it was already called a "battalion". Gathering our studies and experiences together, we aim to describe the policing in stadiums in Rio de Janeiro and its history; bringing the entire trajectory of this battalion and its peculiarities. In the course of the research, we came across the relationship between the military police and the local soccer fans, their ways of controlling them and the divergences between their speech and the practices that guided the actions of the battalion; in this article, it is also explored some themes concerning groups of soccer supporters, their practices, the tensions in the relationship between them and the "BEPE" in the City of Rio de Janeiro, and how do they manage these conflicts in this place full of emotions.
\end{abstract}

Keywords: Policing; Stadiums; Conflict Management.

\footnotetext{
${ }^{1}$ Mestranda do Programa de Pós-Graduação em Justiça e Segurança - Universidade Federal Fluminense, Bolsista CAPES. E-mail: camilag@id.uff.br.

${ }^{2}$ Mestre do Programa de Pós-Graduação em Ciências Sociais - Universidade do Estado do Rio de Janeiro, Bolsista CAPES. E-mail: raqueldeoliveirasousa@hotmail.com.
} 
A temática principal deste artigo é o desenvolvimento histórico da unidade da Polícia Militar do Estado do Rio de Janeiro especializada em atuar no policiamento dos eventos desportivos profissionais que aconteçam no estado do Rio de Janeiro, especificamente no futebol; descrever suas práticas e relações com os torcedores, além de uma breve discussão sobre violência e práticas de torcedores organizados.

Este trabalho foi produzido a partir de uma restrita bibliografia sobre policiamento em eventos esportivos, tendo o trabalho de campo e a pesquisa etnográfica como principais métodos de construção e elaboração da pesquisa. $O$ trabalho de campo se deu em dois momentos diferentes: Em 2017, durante nove meses junto ao Grupamento Especial de Policiamento em Estádios (GEPE), onde foi possível acompanhar toda a rotina diária dos policiais em suas funções administrativas e toda as atividades exercidas em dias de jogos, além do acompanhamento do Curso de Policiamento em Praças Desportivas (CPPD)33. O segundo momento da pesquisa contou com etnografia iniciada em abril de 2019 à dezembro do mesmo ano ${ }^{4}$, sendo realizado também o acompanhamento de toda a rotina dos policiais do batalhão nas funções administrativas e nos dias de jogos, o acompanhamento do novo Curso de Policiamento em Praças Desportivas (CPPD), que contou com alterações significativas em suas atividades, disciplinas e tempo de duração. Para além, foi realizado de um levantamento histórico do GEPE até sua transformação em Batalhão Especializado de Policiamento em Estádios (BEPE), utilizando a metodologia de entrevistas semiestruturadas com policiais (oficiais e praças) do batalhão, com os ex-comandantes do GEPE, e também com Coronéis que exerceram cargos de comando da PMERJ, com o objetivo de compreender qual é a visão da instituição para com o GEPE/BEPE.

A importância dessa pesquisa se dá pelo fato do GEPE/BEPE ainda estar em um campo desconhecido pela maioria da população, inclusive, dos frequentadores de estádios. Mesmo que os torcedores estejam sempre na presença desses policiais,

\footnotetext{
3 Pesquisa realizada para elaboração do Trabalho de Conclusão de Curso para o curso de Bacharelado em Segurança Pública e Social (UFF) pela mestranda Camila Souza Gomes.

4 Pesquisa em curso para a elaboração de dissertação a ser apresentada ao Programa de Pós-Graduação em Ciências Sociais (UERJ) pela mestranda Raquel de Oliveira Sousa.
} 
desconhecem suas ideologias e metodologia de trabalho, não têm conhecimento de como são treinados, não sabem como o batalhão funciona, nem que existem as demais atribuições para além daquelas que veem superficialmente nos estádios. O objetivo geral deste trabalho é apresentar o GEPE, suas práticas e representações, até a sua transformação em BEPE, trazendo ao leitor explicitações do atual trabalho realizado nos estádios. Estudar suas formas de atuação nos estádios cariocas, conhecer sua rotina, modo de administração de conflitos, estrutura administrativa e buscar compreender como se relacionam com as torcidas organizadas.

\section{De grupamento a Batalhão: seu desenvolvimento ao longo do tempo}

O futebol é culturalmente conhecido como a grande paixão nacional. Além da emoção da vitória e da tristeza das derrotas, este esporte traz consigo inúmeros outros sentimentos, representações e influências que ultrapassam as quatro linhas do campo. Interferências externas das relações sociais também podem ser percebidas na sociabilidade do futebol, como por exemplo, a violência presente na sociabilidade das torcidas organizadas; estas estão constantemente estampadas nos noticiários policiais com manchetes de brigas e confrontos. Com o aumento da violência nos estádios, surgiu a necessidade de treinar policiais de forma especializada para atuar em situações conflituosas - nascendo, assim, o Grupamento Especial de Policiamento de Estádios (GEPE), em 1991. Antes de desenvolvermos a trajetória histórica do GEPE/BEPE é necessário destacar que devido à precariedade de documentos, arquivos e produções acadêmicas a respeito dessa temática, as informações aqui apresentadas foram extraídas de livros sobre o coronel Carlos Magno de Nazareth Cerqueira 5 (CERQUEIRA, 2001; LEAL, PEREIRA, MUNTEAL FILHO, 2010), de entrevistas realizadas com policiais que atuam em estádios antes mesmo da criação do GEPE e

\footnotetext{
${ }^{5}$ Coronel Carlos Magno de Nazareth Cerqueira foi Diretor-Geral de ensino e Chefe do Estado Maior da Polícia Militar do Rio de Janeiro durante os anos dois mandatos do governo do Leonel Brizola. Durante o seu comando, a Polícia Militar do Rio de Janeiro seguiu a linha do policiamento comunitário, no qual havia como um dos objetivos uma melhor relação entre a polícia e a sociedade. A partir desse modo de policiamento que surgiu a inspiração de criar um grupamento especial para melhor comunicação com torcedores.
} 
alguns documentos armazenados no próprio batalhão.

Durante os dois governos de Leonel Brizola (PDT), a política adotada pela Polícia Militar do Estado do Rio de Janeiro foi um modelo de policiamento comunitário e defesa do cidadão a partir dos direitos humanos; com isso foram criados centros comunitários, e alguns grupamentos que seguiram esta mesma lógica, como, por exemplo, o grupamento de turismo e também o grupamento para estádios. $\mathrm{O}$ policiamento nos estádios era feito pelo batalhão responsável pelo local do estádio a ser realizada a partida. Parte do efetivo que normalmente faria patrulha na rua era designado ao estádio para fazer a segurança dos torcedores. Não havia nenhum tipo de treinamento especial ou instrução.

Inicialmente chamado de Grupo de Vigilância nos Estádios, quando o coronel Cerqueira ocupava o posto de Chefe do Estado Maior da Polícia Militar do Rio de Janeiro, de 1991 a 1994, o GEPE foi criado a partir da iniciativa de compreender as torcidas organizadas através de grupos de estudos e cursos destinados aos soldados que faziam parte do grupamento (LEAL et al., 2010).

O GEPE era uma companhia do Batalhão de Choque e até hoje tem sua sede localizada no bairro de Deodoro, na cidade do Rio de Janeiro, em um terreno cedido pela empresa ferroviária Supervia. Criado no dia 10 de julho de 1991, através da diretriz $\mathrm{n}^{\circ}$ 010/91 da $3^{\text {a }}$ Seção do Estado Maior Geral, no período do segundo governo Brizola, como uma iniciativa dentre tantas outras que foram promovidas neste momento, sua atuação era restrita somente ao Complexo Desportivo do Maracanã, mas logo ganhou dimensão e sua atuação se estendeu a todos os eventos desportivos, culturais e artísticos ocorridos no Estado do Rio de Janeiro. O Secretário de Segurança e Comandante Geral da polícia na época era o coronel Carlos Magno de Nazareth Cerqueira.

Em junho de 1995, o GEPE foi extinto por meio de uma resolução da Secretaria Estadual de Segurança Pública, no período do governo do Marcelo Alencar (PSDB), sendo refundado dia 20 de janeiro de 1999, em um amistoso entre Flamengo x Fluminense, atendendo aos pedidos da população e da imprensa especializada - como conta o histórico do GEPE fornecido por um dos interlocutores. Este clássico, no dia de São Sebastião, marcava a reabertura da geral do Maracanã depois de 4 anos. Porém, o 
ato normativo só foi oficializado no dia 03 de fevereiro de 1999. Era o início do governo do Anthony Garotinho (PDT).

Em 31 de julho de 2018, através da resolução SESEG № 1.213, publicada no Diário Oficial, o GEPE tornou-se Batalhão Especializado de Policiamento em Estádios (BEPE), sem aumento de efetivo e despesas, no governo de Luís Fernando Pezão (PMDB). A estruturação para tal passo vem sendo realizada ao longo dos anos a partir de cada comando que o GEPE possuiu.

Até a formação do BEPE, este grupamento respondia, administrativamente, ao Batalhão de Polícia de Choque (BPChq/PMERJ). Havia uma autonomia quanto à operacionalidade do GEPE, que respondia ao Comando de Policiamento Especializado (CPE). Após tornar-se um batalhão, continua respondendo administrativa e operacionalmente ao CPE. Esse comando é composto por alguns batalhões, como Batalhão de áreas Turísticas (BPTur), Batalhão de Policiamento de Vias Expressas (BPVE), Regimento de Polícia Montada (RPMont), entre outros. Um coronel, excomandante do GEPE afirmou em entrevista que sentia que o GEPE, em seu início, estava em um "limbo", onde não se sabia ao certo sua localização no organograma da PMERJ.

A realização de grandes eventos na capital do estado, como a Copa do Mundo em 2014 e os Jogos Olímpicos em 2016, foi primordial para uma série de mudanças no policiamento em estádios no Rio de Janeiro, tanto para recebê-los, quanto no que se refere às mudanças posteriores que foram mantidas. Dentre elas podemos citar: 1) a presença da segurança privada nos estádios; 2) o CPPD; 3) a gratificação a os policiais; 4) a elitização dos jogos; 5) aumento do uso de equipamentos menos letais.

A presença da segurança privada, popularmente conhecido como stewards, se deu com a chegada dos grandes eventos esportivos ao país, iniciando com a Copa das Confederações, em 2013. A partir deste momento os stewards passam a atuar nos estádios em conjunto com a polícia militar. Atualmente, eles realizam a segurança do patrimônio interno, assim como as revistas dos torcedores, que antes eram realizadas pelos policiais do GEPE.

O Curso de Policiamento em Praças Desportivas (CPPD) é o curso de especialização do GEPE, onde são passados treinamentos específicos e focados na 
atuação em estádios, além das matérias teóricas que abrangem o Estatuto do Torcedor, Estatuto do Desarmamento, Psicologia das Multidões, e até mesmo Direito Penal, ministradas por professores universitários voluntários, como também pelos departamentos de instruções dos batalhões em que o CPPD percorre (diversas unidades policiais colaboram com o CPPD compartilhando algumas de suas práticas com os alunos, como o Batalhão de Choque e até mesmo algumas unidades de outros estados).

O curso foi criado em 2012, quando uma queda na qualidade do serviço foi percebida pelos oficiais da época, como me relata em uma entrevista o Cap N, um dos idealizadores do curso. Para modificar esse quadro era necessário subir o nível do serviço prestado, padronizando as condutas dos policiais e assim, criando o Curso de Policiamento de Praças Desportivas. O curso acontecia no final do ano, época em que acontecem grandes eventos esportivos. Sendo assim o efetivo não era comprometido. Com a devida autorização, podemos acompanhar algumas etapas do curso, como, por exemplo, a instrução de tiro e o treinamento de segurança de autoridade, realizados no CFAP (Centro de Formação e Aperfeiçoamento de Praças), bem como um treinamento de controle de distúrbio civil, no qual simulava-se uma manifestação de rua, realizado no Quartel do Batalhão de Choque (BPChq).

Após a transformação de GEPE para BEPE, o CPPD passou por algumas mudanças, a principal delas foi a ampliação da duração. Anteriormente, o curso era realizado em 45 dias e este ano o curso foi estendido oficialmente para três meses de duração. Não sendo realizado ao fim do ano, a décima edição do CPPD iniciou no início do segundo semestre, em julho. Porém a formatura foi realizada no início de outubro de 2019. Para o ingresso no curso é necessária uma boa classificação no Teste de Aptidão Física (TAF) da própria PMERJ. Apesar da lógica de criação do GEPE, de um policiamento comunitário, o curso de especialização não difere muito da lógica de outros cursos de polícia demonstrada Silva (2009) e Storani (2008). Há a simbologia do "tocar o sino" como sinônimo de desistir do curso, orações que os alunos são obrigados a decorar e as "sugas", como modo de cansar os alunos e fazê-los desistir também estão presentes.

Todavia, este curso não é obrigatório a todos os policiais do batalhão. Os 
cursos obrigatórios para o efetivo do batalhão são uma série de módulos de capacitação continuada. Estas instruções, geralmente, ocorrem com uma hora de antecedência do horário normal em que os policiais chegam para o policiamento em um dia de jogo.

À época foi, outra maneira de valorizar e estimular o GEPE, foi a instituição da gratificação dos policiais lotados nesta unidade, a partir de 2011, com o valor de R\$1.0oo. Um dos entraves para a transformação do grupamento para batalhão foi a preocupação com os gastos. Entretanto, o Comandante da unidade no período, juntamente com o Chefe do Estado Maior, em 2018, conseguiram apresentar ao ViceGovernador Francisco Dornelles (PP) a constatação de que não haveria alteração nos gastos públicos.

O aparato técnico melhorou ao longo dos anos e não foi diferente com os equipamentos hoje disponíveis após a transformação do GEPE em BEPE: diferentes tipos e tamanhos de granadas, elastômero, teaser, dentre outros tipos de armamento menos letais. Além de todas essas mudanças advindas após os grandes eventos, há uma mais marcante, que já vinha sendo implementada desde as reformas do Maracanã para o Pan Americano em 2007. Com essas obras foi estabelecido, sem consulta popular, o fim da "geral"6 do Maracanã - setor que possuía o menor valor de ingresso. Ali se faziam presentes uma série de torcedores icônicos e as classes mais populares. Após as obras, com o fim da geral, não há mais um setor com ingressos tão baratos7; o valor médio do ingresso subiu consideravelmente e com isso as classes populares foram alijadas dos jogos. Esses se tornam um meio mais elitizado e, de acordo com relatos em entrevistas, mais fáceis de policiar.

\subsection{Estrutura enquanto GEPE}

Administrativamente, o GEPE se dividia em seções como um batalhão convencional, possui oficial de dia, despachante, sala de material bélico, policiais na

\footnotetext{
${ }^{6}$ É válido ressaltar que a lei № 8.575/19 foi sancionada pelo então governador Wilson Witzel (PSC), a qual autoriza o retorno da geral do Maracanã nos setores norte e sul.

${ }^{7}$ Os preços praticados pela geral eram em torno de centavos a $\mathrm{R} \$ 2$, enquanto atualmente, o ticket médio dos ingressos para setores populares são aproximadamente $\mathrm{R} \$ 50$. Sobre os valores dos ingressos ver: SIMÕES, 2017.
} 
guarda em escalas de $24 \mathrm{~h}$ etc. Além das funções administrativas, o GEPE tinha um projeto chamado Projeto GEPE pela Paz, que tinha como responsável a soldada L. que atendia a crianças da comunidade situada próximo ao batalhão.

O GEPE contava com cerca de 220 policiais, incluindo os afastados, de férias, de licenças especiais, etc. A tropa possuía aproximadamente 110 policiais, incluindo a força de escolta, escolta de delegações, pinças e os policiais que ficam espalhados pelo estádio, estes se fazem presentes em toda extensão das arquibancadas e dentro do campo, prontos para atuar em qualquer princípio de confusão e são auxiliados pelos policiais de apoio, que são policiais de outros batalhões escalados para reforçar o trabalho do GEPE. Os pinças são responsáveis pela segurança dos árbitros da partida, ficam dentro do campo e recebem treinamento diferenciado (além do curso de especialização, recebem treinamento de proteção de autoridade, técnicas de defesa com as mãos, sem armas, etc). A escolta de delegação é responsável pela segurança das equipes no trajeto até o estádio e a força de escolta é responsável pela escolta das torcidas organizadas.

A força de escolta era considerada por muitos policiais o "carro-chefe" do GEPE, o trabalho mais importante e que mais exigia de seus policiais. Era a força de escolta que utilizava os armamentos mais pesados, como as armas de disparo de bombas de gás-lacrimogênio, por exemplo. Tamanha importância deve-se ao fato de que as brigas entre torcidas organizadas passaram a acontecer no trajeto das mesmas até os estádios, muitas delas marcadas pela internet, como me contou um de meus interlocutores que atua na força de escolta.

O trabalho da escolta se torna ainda mais importante e perigoso quando se trata dos jogos que envolvem clubes de outros estados e possuem grandes torcidas. Nesses casos, o GEPE entrava em contato com as torcidas organizadas do clube que virá jogar no Rio de Janeiro para acertarem detalhes da escolta.

O padrão de escolta realizado pelo GEPE para as torcidas visitantes, como são chamadas as torcidas organizadas que vêm de fora do estado, era elogiado por quase todos os torcedores visitantes que pude entrevistar. Os torcedores cariocas costumavam dizer que "O GEPE é uma mãe pra quem vem de fora", pois, segundo eles, a polícia dos outros estados não têm tanto cuidado quanto o GEPE. Conversando sobre 
essa questão com, à época subcomandante major Faulhaber, ele explica que proteger e preservar a integridade física dos torcedores era o objetivo principal do GEPE, sendo assim, buscavam evitar todo e qualquer tipo de confronto, inclusive nas áreas distantes dos estádios. Segundo ele, foram muitos os casos de brigas entre torcidas organizadas que aconteceram no trajeto que uma torcida de fora do Rio de Janeiro fazia até o estádio em que seu time jogaria. Casos de emboscadas armadas por torcidas cariocas são comuns e o GEPE buscava diminuí-los cada vez mais. Para isso, faziam contato com as torcidas visitantes, marcam um ponto de encontro próximo à divisa de seus estados de origem, onde realizam revista em todos os torcedores e em todos os veículos (geralmente vêm em caravanas de ônibus ou vans) e seguem escoltando-os até o estádio, sempre traçando os melhores caminhos para que não encontrem com nenhuma torcida rival.

\subsection{Estrutura enquanto BEPE}

As funções operacionais realizadas enquanto GEPE seguem sendo realizadas após a transformação do grupamento em Batalhão, tendo a criação da Força de Choque e o policiamento da área externa como as principais mudanças nessa transformação, assim como mudanças significativas no CPPD. O comando do GEPE permanece, assim como o efetivo administrativo e a tropa. Possíveis alterações no quadro de policiais não se deram devido à mudança em si.

A força de choque, criada juntamente à fundação do batalhão, passa a ser vista como a "tropa de elite" do BEPE, segundo a opinião do ex-comandante tenente-coronel Silvio. Criada para ser a última força de atuação do BEPE, sendo acionada quando não há outra maneira de resolução de um conflito, geralmente, realizam rondas no entorno do estádio. Estes policiais portam os elastômeros, usam a proteção de capacete, assim como uma roupa de proteção e são os mais armados da tropa. Em jogos onde não há o grande apelo esta força é acionada em último caso, quando outros policiais do BEPE não conseguem resolver a questão.

Ao prestar segurança em um jogo de futebol, o BEPE não atua sozinho; conta com uma série de policiais de apoio. Estes apoios são policiais de diversos batalhões 
(de área ou especializados) ou alunos do Centro de Formação e Aperfeiçoamento de Praças (CFAP). Também conta com a atuação conjunta com outros batalhões, como o Batalhão de Ações com Cães (BAC), atuando dentro do estádio, próximo da arquibancada; Regimento de Polícia Montada (RPMont), que atuam na área externa dos estádios; e, dependendo do apelo e importância do jogo, o Batalhão de Polícia de Choque (BPChq) também atua. É interessante destacar que quase todos os policiais que estão trabalhando nos jogos colocam o braçal do BEPE. Entretanto, os policiais de batalhões do Comando de Operações Especiais (COE), não utilizam o braçal com o emblema do BEPE; são o BAC e o BPChq. O que diferencia os policiais lotados no BEPE, para todos os outros policiais de apoio é o equipamento branco (cobertura, cinto tático e coldre).

Hoje no BEPE não existe mais o Projeto GEPE pela Paz, através do qual se oferece o reforço escolar; entretanto, continua possuindo projetos que envolvem a comunidade do entorno. O primeiro e o mais atuante são as aulas de kickboxing, realizadas por um sargento que está há mais de dez anos na unidade e é faixa preta neste esporte. O público principal são adolescentes (a partir dos 16 anos) e adultos da comunidade. O segundo projeto, mas não menos importante, são as aulas de futebol para crianças e adolescentes até 14 anos. Estas aulas ocorrem duas vezes por semana, assim como as aulas de arte marcial, e são dadas por um policial cabo que está a menos de cinco anos no batalhão, graduado em Educação Física.

\subsection{Violência e Torcidas Organizadas}

Utilizando-se de instrumentos musicais e uniformes, as primeiras torcidas aparecem como grupos de torcedores que apoiavam seus clubes de maneira alegre e festiva. Estes grupos passaram a ser chamados de "charanga" e possuíam um torcedor chefe, que era o torcedor-símbolo daquela torcida. (PALHARES, et al, 2012).

O modelo de torcer implementado pelas torcidas uniformizadas/charangas dominou o cenário dos estádios até o final dos anos 6o. A consolidação do futebol brasileiro mundialmente após duas conquistas internacionais, impulsionaram novas formas de torcer (diferentes da maneira mecânica das torcidas uniformizadas 
defendidas como padrão de comportamento a ser seguido). Um novo formato, mais popular e mais autônomo, ganhou espaço e apelo entre os torcedores das classes populares (TOLEDO, 2000).

As primeiras torcidas organizadas com modelo mais conhecido atualmente, são datadas no final da década de 6o e início dos anos 7o, período em que o Brasil dava largos passos na busca do desenvolvimento econômico e cidades como Rio de Janeiro e São Paulo avançavam no processo de aceleração urbana. O estilo de vida que os jovens dessa época levavam não pode ser dissociado dos desdobramentos causados por essas questões político-econômicas. O conflito entre os poderes econômico e social marcou a construção do espaço urbano das grandes cidades, prevalecendo o interesse do capital. Esse processo interferiu de alguma forma, na identidade social dos jovens que se expressam através da negação do outro enquanto ser social, da disputa e da violência prazerosa entre grupos rivais (PIMENTA, 2000).

Superando a fase das torcidas uniformizadas e dos torcedores-símbolo enquanto representações idealizadas e romantizadas de torcer, o surgimento das Torcidas Organizadas acompanhou as mudanças políticas do país, estabelecendo, aos poucos, novas formas de sociabilidade e de vivência do futebol enquanto lazer e hábito, construindo e firmando um modo diferente de torcer daquele usualmente observado até então. O surgimento de um novo padrão de comportamento deve ser contextualizado no cenário das transformações ocorridas com o futebol ao longo dos anos dentro da sociedade brasileira. As torcidas que eram inicialmente representadas e personificadas em torcedores-símbolos agora são representadas por coletividades autônomas, impessoais, criando relações diferentes entre torcidas, dirigentes e imprensa. (TOLEDO, 1996).

Foi nos anos de 1992 e 1994 que ocorreu a maior parte dos envolvimentos noticiados entre torcidas organizadas, que resultaram na morte de doze pessoas; quatro em 1992 e oito em 1994. Os confrontos passaram a ser constantes nesse período e os instrumentos utilizados para defesa e ataque eram capazes de causar lesões graves. Os torcedores organizados começaram a fazer uso de bombas caseiras e armas de fogo. (PIMENTA, 2000) 
As torcidas organizadas são instituições que existem legal e burocraticamente, pois possuem CNPJ e estão cadastradas no Batalhão Especializado em Policiamento em Estádios (BEPE) junto ao Ministério Público, e se organizam hierarquicamente, tendo presidente, vice-presidente, diretores. De uma maneira geral as principais torcidas organizadas do Rio de Janeiro têm essa estrutura. A hierarquia se faz presente não só pela existência desses cargos administrativos, mas também através do status que cada torcedor adquire dentro dela.

Os torcedores que fazem parte da bateria, por exemplo, são responsáveis por puxarem as músicas na arquibancada e manter o ritmo do canto da torcida - são geralmente torcedores que não se envolvem em brigas e que têm o respeito de todos que fazem parte da torcida. "O material" também é um segmento de grande importância na torcida e eleva o status do integrante. Responsáveis por todo material da torcida, é considerada a área de maior responsabilidade e comprometimento com a torcida. Além de não se envolverem em brigas, os torcedores responsáveis pelo material entram no estádio antes mesmo do estádio abrir, arrumam todas as faixas e bandeiras em seus devidos lugares, e ao final da partida são os últimos a deixarem o local, retirando em segurança todo o material.

As torcidas organizadas são constantemente associadas à violência nos estádios de futebol tendo a mídia como principal reprodutora deste senso comum. Observando o problema de fora, essa é realmente a imagem construída desses torcedores e de suas práticas.

O conceito de violência não é simples de ser definido. Yves Michaud (1989) traça quatro pontos para compreender melhor este conceito: 1) as definições de violência são baseadas em pressupostos e não é capaz de explicar todas as características que a envolvem. 2) É composta por ideias subjetivas e podem ser alterados a partir de diferentes critérios (moral, jurídico, entre outros). 3) Existem diferentes perspectivas sobre a violência e, em geral, não existe um equilíbrio entre as diferentes visões. 4) Portanto, não há um saber universal, ou discurso uno sobre a violência.

As classificações sobre o que é um ato violento variam conforme as diferentes tempos históricos, sociedades e culturas, isso é, não é um conceito concreto, mas uma 
categoria empírica; são representações sociais da violência (MISSE, 2016, PORTO, 2010). A violência pode ser expressa por diferentes modos, como a violência institucional, a violência estrutural, ou a violência individual (DOMINGUEZ et. al., 2002). Dentro de um estádio de futebol existem distintas formas e representações de violência, no entanto, na maioria das vezes a única forma de violência lembrada e fortemente citada são as brigas entre torcidas organizadas de futebol. Faz-se necessário refletir sobre o peso em que a sociedade imputa sobre um indivíduo e suas ações, a partir de sua caracterização e identificação com uma torcida organizada. Seus atos, frequentemente, recebem mais atenção midiática e possuem maior repercussão perante a sociedade.

A palavra violência é originada do latim, associada a força, recursos para exercer a força vital, vigor: "Esta força torna-se violência quando ultrapassa um limite ou perturba acordos tácitos e regras que ordenam relações, adquirindo carga negativa ou maléfica." (ZALUAR, 1999, p. 8). A negatividade que a palavra violência carrega é inegável, nos remetendo imediatamente a ilegalidade, crueldade, mau-caratismo de quem a pratica. Não soa como correto alguém praticar e gostar de violência, mas a prática da violência não pode ser analisada sem levar em conta todas as variáveis sociais presentes nela. Neste artigo, a categoria violência se refere aos casos de brigas e agressões físicas praticadas pelas torcidas organizadas, dentro ou fora dos estádios, contra torcedores rivais.

Tendo como base o conceito das categorias "sujeito" e "bandido" de Michel Misse, onde o bandido seria "o sujeito criminal produzido pela interpretação da polícia, da moralidade pública e das leis penais" (MISSE, 2010, p 17), no universo dos estádios e torcidas organizadas, o bandido seria o torcedor que briga, que passa a ser chamado, principalmente pelos policiais, de vândalo ou marginal.

Neste cenário, os conceitos "vândalo" e "marginal" são usados como sinônimos para destacar que pessoas que cometem atos violentos não podem ser consideradas torcedoras, e que, segundo alguns policiais me relataram durante a pesquisa de campo, os "marginais" seriam minoria em relação a tantas "pessoas de bem" que frequentavam os estádios, mas eram uma minoria que tinha capacidade pra fazer um "estrago grande”. 
Segundos relatos de um torcedor, durante uma entrevista, dentro das torcidas existem torcedores que estão ali pela festa na arquibancada, pelo prazer de apoiar seu time através dos cânticos e coreografias tradicionais que cada canção carrega:

Existe dois tipos de torcedores organizados. Um que vai pro estádio e fica na arquibancada onde a organizada fica e o outro que faz parte dos grupos nas cidades. (...) A grande maioria eu acho que prioriza festa na arquibancada (Torcedor F).

Diferente da categorização dos próprios torcedores, durante as etnografias os policiais classificavam os torcedores em três categorias: o torcedor comum, aquele que não possui vínculo com torcida organizada; o torcedor organizado de festa, que se relaciona ao "que prioriza festa na arquibancada." (Torcedor F); e os "baderneiros", "marginais", "vândalos" que são os de torcida organizada que brigam. Entre os torcedores de festa, geralmente, os policiais classificam os movimentos populares de torcedores de inspiração nas torcidas sul-americanas ${ }^{8}$.

A violência entre torcidas se mostra mais como uma disputa de poder nos territórios do que motivada pela diferença entre seus times. Segundo Zaluar (2014), o poder é a dominação que falsamente estabelece a assimetria de poder entre dominantes e dominados. Todo poder é violento, pois é baseado na violência simbólica, e tem como matriz a dominação masculina, chamada de ethos da masculinidade, que obriga o homem a ocupar a posição de dominador (Bourdieu, 2005).

O poder que uma torcida acredita ter sobre um determinado bairro só existe no contexto das torcidas organizadas. Só reconhece o domínio da torcida $\mathrm{X}$ sobre o bairro Y quem faz parte de todo esse universo de torcidas. Não há imposição de regras para moradores, não há construção de barricadas, espaços físicos que determinem que aquele bairro é dominado pela torcida X. Além de alguns muros pichados com siglas e bordões das torcidas, nenhum outro sinal físico comprova qualquer tipo de dominação e poder naquele território.

\footnotetext{
${ }^{8}$ São torcidas que possuem o estilo sul-americano de torcer, de inspiração das torcidas "barras", mas sem as categorias de perigo e violência. Para maiores informações sobre movimentos populares torcedores Teixeira (2013).
} 
O sentimento de família e lealdade para com aqueles que estão ao seu lado aparece como forte motivação para entrarem em confrontos e permanecerem na torcida:

\begin{abstract}
Meu time e minha torcida são parte da minha vida, são como se fossem membros da minha família e ao longo da nossa jornada fazemos amigos na pista que acabam virando nossos irmãos de camisa (Torcedor $\mathrm{O}$ ).
\end{abstract}

Eu gosto [de brigar]... Mas a adrenalina e os amigos são minha motivação maior. Antigamente gostava de bater nos outros, hoje já brigo mais pelo nome do bonde, já não bato mais em qualquer um por bater. Batia porque tinha ódio mesmo [...] (Torcedor E).

As amizades feitas são verdadeiras alianças, os amigos são considerados aliados, pessoas importantes o suficiente para colocar em risco sua própria vida. Opostos aos aliados estão os integrantes das torcidas rivais: os inimigos, "os alemão", “os caras”. A rivalidade entre as Torcidas Organizadas ultrapassa a rivalidade existente entre os times dentro de campo, torna-se uma questão de defender a honra de sua torcida e de seus aliados:

A partir do momento que você está ali, é necessário fazer o certo para proteger você e seus amigos, independente de quem sejam seus adversários e das consequências dos seus atos (Torcedor N).

O ato de brigar é uma demonstração de lealdade para com os amigos e de fidelidade à instituição. Ir para a "guerra", como eles costumam se referir aos confrontos, é uma prova de que você realmente se dedica a sua torcida.

O cara que briga sempre vai ser o mais falado, o mais indicado. Quando você não vai pra guerra você se sente até mal. Você pensa que seus irmão (sic) tão e que você não tá, vira meio que uma obrigação dentro de você. Você deixa família, deixa tudo sem pensar (Torcedor E).

Além de toda a questão da lealdade, participar de confrontos proporciona ao integrante da torcida um status que significa muito dentro daquele contexto. Ser o “cara bom de porrada" é um elogio dos grandes, que conta muito para que um torcedor seja líder do seu bairro, por exemplo, chame atenção de algumas garotas, receba ingressos de cortesia para os jogos. Depois de se tornar conhecido na torcida, é preciso 
manter a postura que o fez chegar até ali, caso contrário, em pouco tempo aparece outro melhor. Para alguns torcedores entrevistados, as brigas "fazem parte do jogo" e podem acontecer com qualquer um, inclusive com quem não é da torcida, mas não são a motivação principal de estarem ali.

\section{Fundamentação teórica}

Segundo Egon Bittner, em "Florence Nightingale Procurando Willie Sutton: Uma Teoria da Polícia” (2003), dentre as instituições do governo moderno, a polícia desperta um interesse especial: ao mesmo tempo em que é a mais conhecida pela população, é também a menos compreendida, pois as pessoas são incapazes de ir além do lugar comum mais superficial quando são questionadas a respeito dos fins do serviço policial.

O lugar comum é que o trabalho da polícia seja resumido como "combater o crime", deixando de lado todas as demais atribuições que lhe cabem, por exemplo, garantir a ordem em um determinado local, garantir que os direitos dos cidadãos sejam preservados e até mesmo prestar pequenos serviços de ajuda à população, além de suas funções administrativas internas.

A Polícia Militar do Estado do Rio de Janeiro conta com mais de cinquenta batalhões, além das Unidades Especiais e Especializadas do Comando de Operações Especiais (COE) 9 e o Comando de Policiamento Especializado (CPE) ${ }^{10}$, e, como me relata um dos oficiais com quem podemos conversar durante as pesquisas de campo, o policiamento criminal é o que recebe mais atenção e importância.

Segundo a definição de Bayley (2001, p.24), "uma força policial especializada se concentra na aplicação de força; uma força policial não especializada possui

\footnotetext{
9 Comando de Operações Especiais (COE) compreende as seguintes unidades: Batalhão de Policiamento de Choque (BPChq), Batalhão de Operações Especiais (BOPE), Batalhão de Ações com Cães (BAC), Grupamento Aeromóvel (GAM) e o Centro de Instrução Especializada e Pesquisa Policial (CIEsPP).

${ }^{10}$ Comando de Policiamento Especializado (CPE) compreende o Batalhão de Policiamento em Áreas Turísticas (BPTur), Rondas Especiais e Controle de Multidões (RECOM), Batalhão de Polícia Rodoviária (BPRV), Batalhão de Policiamento de Vias Expressas (BPVE), Grupamento de Policiamento Ferroviário (GPFer), Regimento de Cavalaria Coronel Enyr Cony dos Santos (RCECS) e o Batalhão Especializado de Policiamento em Estádios (BEPE).
} 
autorização para fazer uso de força, mas é capaz de fazer muitas outras coisas também.". Para melhor encaixar essa definição nas unidades do COE e do CPE da Polícia Militar, devemos entender "aplicação de força" como aplicação de força num segmento específico. O Batalhão Especializado de Policiamento em Estádios, por exemplo, tem como prioridade a aplicação da força nos eventos desportivos profissionais que acontecem em todo território do estado do Rio de Janeiro. Bayley resume uma polícia especializada como aquela que dedica toda a sua atenção à aplicação de coerção física, mas o BEPE, mesmo sendo considerado uma polícia especializada, dedica sua atenção ao uso de outras formas de ação, para além da coerção física citada por Bayley.

Certa vez, em conversa com o tenente E. ${ }^{11}$, o mesmo atentou para uma simples diferença de nomenclatura, mas que para ele tem uma relevância significativa: Quando se diz que um grupamento é especial, ele é apenas um grupamento que foi designado a atuar numa função específica, no caso do Grupamento Especial de Policiamento em Estádios (GEPE), em um local delimitado, as praças desportivas. Mas quando falamos em um grupamento especializado, estamos falando de um grupamento que tem capacitação diferente dos demais para determinada função. Apesar do GEPE ter em seu nome o termo 'especial', sempre foi considerado por seus policiais como um grupamento especializado em policiamento em estádios, pois foram treinados e preparados de forma específica para esse tipo de serviço. Essa diferença pôde ser notada no trabalho de campo, onde foi possível descobrir que os policiais do GEPE recebem apoio de policiais de outros batalhões (esses sem qualquer tipo de treinamento para atuar em estádios) e que, muitas vezes, são esses policiais cedidos que acabam agindo de forma diferente daquela padronizada pelo GEPE. Com a transformação em BEPE a nomenclatura que antes era especial, passou a ser especializado.

Em conversa com o subtenente $M$. que atua em estádios antes mesmo da criação do GEPE o mesmo relatou como era o policiamento naquela época e o que mudou até os dias atuais. Segundo ele, a estrutura em si foi o que mais mudou:

\footnotetext{
${ }^{11} \mathrm{~A}$ identidade dos interlocutores foi preservada por questão de privacidade dos mesmos. Somente alguns foram identificados por ocuparem posições de comando.
} 
Antigamente, no início, o GEPE não tinha uma sede física própria, não tinha toda a estrutura interna administrativa, não tinha tantos policiais, era basicamente formado por cabos e soldados, tinham um ou dois oficiais, não tinha o serviço de inteligência que hoje é fundamental para o sucesso do trabalho feito, não faziam escolta de delegações e das torcidas organizadas (Entrevista com o subtenente M. em 26/05/2017).

O subtenente segue dizendo que inicialmente não tinham nem o bastão para usar, depois ficaram um bom tempo usando somente o bastão, não tinham gás de pimenta, gás lacrimogênio e nenhum dos demais armamentos menos letais que o GEPE utilizava no momento. Durante a conversa, o subtenente se lembrou de um jogo no Maracanã que segundo ele devia ter aproximadamente 200 mil pessoas para 80 policiais totalmente despreparados para lidar com aquele ambiente específico. Hoje, além do número de público ter sido reduzido devido a diversos fatores (estádios menores, ingressos a preços elevados, etc), os policiais são treinados e especializados para atuarem em estádios.

O principal objetivo do GEPE nos estádios, como descreve o próprio comandante em uma de nossas entrevistas era a prevenção, evitar que brigas aconteçam e não mais entrar em confronto com as torcidas, como acontecia antigamente. O GEPE buscava prender os torcedores envolvidos nas brigas e não mais entrar em confronto, pois, como acredita o comandante, só assim os casos de brigas irão diminuir.

Apesar dos eventos esportivos serem de cunho privado, onde a segurança não deveria ser feita pela Polícia Militar, a presença da mesma passa a ser exigida com a implementação do Estatuto do Torcedor, criado em 2003, em seu Art $1^{\mathbf{0}}$ que coloca a prevenção da violência dos estádios sob responsabilidade do poder público.

Art. $\mathfrak{1}^{\mathbf{0}-A}$. A prevenção da violência nos esportes é de responsabilidade do poder público, das confederações, federações, ligas, clubes, associações ou entidades esportivas, entidades recreativas e associações de torcedores, inclusive de seus respectivos dirigentes, bem como daqueles que, de qualquer forma, promovem, organizam, coordenam ou participam dos eventos esportivos (Incluído pela Lei no 12.299, de 2010) (LEI № 10.671, DE 15 DE MAIO DE 2003).

Essa recomendação, apesar de prever o compartilhamento de competências 
com entidades esportivas, organizadores e torcedores, confere mandato para a polícia agir nos eventos esportivos, sem delimitar claramente as atribuições e funções de cada instituição. Nesse sentido,

A polícia é uma resposta ao desafio de produzir enforcement sem que este leve à tirania ou passe a servir interesses particulares. Por essa razão, o uso de força pela polícia tem um propósito político distintivo e invariante: produzir alternativas de obediência com consentimento social, sob o Império da Lei. Isso corresponde a uma destinação do uso da força para fins restritos e transparentes, de tais maneiras e com tais controles que o salvaguarde de se converter numa ferramenta de opressão ou num instrumento a serviço de indivíduos ou grupos de poder. Essas salvaguardas configuram os termos específicos do mandato policial para uma determinada comunidade política (polity), num determinado momento (MUNIZ; PROENÇA, 2014, p. 407).

O policiamento nos estádios sendo realizado por um grupamento policial treinado especificamente para estes eventos garante que haja imparcialidade e legitimidade por parte daqueles que são responsáveis pela segurança e por estarem sob o "Império da Lei", possuem o consentimento social daqueles a quem estão servindo. Em geral, o policiamento feito apenas pelos seguranças privados não possuem credibilidade perante os torcedores, eles não se sentem seguros se a segurança nos estádios fosse feita apenas por seguranças privados. Ainda assim, os torcedores demonstram não sentir total segurança com os policiais militares e que, segundo eles, alguns tumultos nas arquibancadas seriam provocados pelas ações dos próprios policiais, que já se aproximam de forma violenta e agressiva.

\section{Resultados alcançados}

Sob o mesmo comando há 5 anos (desde quando era GEPE), concluído no ano de $2 \mathbf{2 0 2 0}^{12}$, o BEPE adota um discurso de prevenção, de aproximação e diálogo com as torcidas. Durante muitas conversas com o comandante do batalhão, ele costumava dizer que a relação entre o BEPE e as torcidas é uma "via de mão dupla", na qual, basta

\footnotetext{
${ }^{12}$ Apesar de atualmente ser outro comandante, ainda não foi possível notar rompimentos de linha de comando por dois motivos: 1) pela pandemia e o decorrente afastamento dos torcedores dos estádios; 2) o atual comandante exercia o cargo de subcomandante até sua promoção.
} 
a torcida colaborar com o BEPE, que o BEPE colabora com as torcidas. Porém, somente a polícia tem a legitimidade da força, assim um lado da "via" acaba tendo maior controle sobre o outro. Com o argumento de promover a segurança dos torcedores, a polícia na verdade está exercendo controle.

Na semana que antecede um "clássico" (partida disputada entre os clubes de maior expressão), o BEPE promove uma reunião no próprio batalhão, na qual as torcidas organizadas dos clubes que se enfrentarão devem enviar seus representantes. Nesta reunião são definidos os locais de onde cada torcida sairá com a escolta, o horário, quais materiais não serão permitidos, entre outros detalhes que o comandante achar relevante passar às torcidas. Apesar de abrir espaço para os torcedores colocarem suas demandas, estas só serão atendidas se o comandante achar que a torcida fez por merecer.

A escolta das torcidas é uma das principais funções do BEPE. Cada torcida tem seu lugar determinado de "concentração" antes do jogo, de onde só podem sair em direção ao estádio na presença da escolta realizada pelo BEPE, que geralmente é feita a pé. Desta forma, o BEPE exerce controle desses torcedores no trajeto até o estádio, determinando qual caminho devem seguir, ainda que muitas vezes os torcedores não estejam de acordo.

De acordo com o Art $2^{\mathbf{0}-A}$ do Estatuto do Torcedor, as torcidas organizadas devem ter seus membros cadastrados, porém não especifica por qual instituição este cadastro deve ser realizado, sendo assim, o BEPE tomou esta atribuição para si. Além do Estatuto do Torcedor, as torcidas organizadas recentemente assinaram um Termo de Ajustamento de Conduta (TAC) junto ao Ministério Público, a pedido do BEPE, visto que, segundo o próprio comandante, o estatuto não seria suficiente para evitar que os torcedores não entrassem em conflito.

Foram 35 torcidas organizadas relacionadas aos quatro clubes de maior investimento do Estado do Rio de Janeiro (Vasco, Fluminense, Botafogo e Flamengo) que assinaram o $\mathrm{TAC}^{13}$, comprometendo-se a seguir as condutas ali definidas e tendo consciência das consequências em caso de descumprimento.

\footnotetext{
${ }^{13}$ Inquérito Civil no 1149/10, 1161/10, 1163/10, 1165/10, 1167/10, 1169/10, 1181/10, 1183/10, 1187/10 e 1189/10.
} 
O controle de materiais das torcidas também é exercido pelo BEPE que por sua própria vontade, determinou que as torcidas só poderiam entrar com seus materiais no estádio (bandeiras, faixas e instrumentos) se enviassem ao BEPE um cadastro de todos os seus membros. A quantidade de material liberada seria de acordo com a quantidade de membros cadastrados. Esta função não está designada ao BEPE no Estatuto do Torcedor, a principal lei de proteção e garantias do torcedor nos estádios, assim, tal como a escolta, o controle de materiais é apenas mais uma forma de tentar controlar os torcedores organizados.

Por várias vezes os oficiais foram questionados sobre a legalidade desse controle em relação aos materiais, se estaria determinado em algum documento que era realmente o BEPE quem deveria exercê-lo, e a quantidade de cadastros que cada torcida deveria ter para liberar a quantidade $\mathrm{X}$ de materiais. Eles sempre me respondiam de maneira desconfortável, dizendo que não, que realmente não havia nada que definisse objetivamente, que era total a critério do BEPE.

Quando alguns torcedores relataram a respeito deste assunto, foi notório que a indignação e o questionamento e sobre como tais medidas podem prevenir alguém de brigar. Eles não sentem que a polícia está ali pela segurança deles, mas sim para controlá-los, intimidá-los. Muitas vezes se sentem injustiçados, pois acreditam que algumas torcidas são mais beneficiadas que outras e, como as decisões do BEPE são sempre subjetivas, não têm muito como argumentar contra.

\section{Considerações finais}

Através de uma breve apresentação histórica baseada em escassa bibliografia, diversas entrevistas e muitas idas à campo, o objetivo deste artigo foi possibilitar ao leitor, de forma clara e objetiva, o conhecimento da história e das atribuições do atual Batalhão Especializado em Policiamento em Estádios, desde sua criação como grupamento até os dias atuais e sua relação com torcedores.

Durante o trabalho realizado em campo junto a torcedores foi possível notar, através de breves conversas e algumas entrevistas, que a maioria dos frequentadores de estádios não entendiam muito bem quais eram as funções e atribuições da polícia 
militar dentro dos estádios, questionando muitas vezes a capacidade de atuação daqueles policiais nos ambientes desportivos junto ao grande público, sendo constantes os comentários de que os policiais não eram bem treinados.

Neste artigo buscamos trazer ao leitor as informações colhidas durante meses de trabalho de campo junto aos policiais acreditando que o despreparo dos mesmos não seja mais o argumento para justificar más atuações que possam vir a ocorrer no exercício de suas funções junto aos torcedores. Assim como, através do relato do que foi observado junto às torcidas organizadas, explicitar formas de controle por parte dos agentes do Estado que nos mostram que apesar de ser um batalhão especializado, reproduz as práticas e lógicas da polícia militar.

Concluímos, mostrando que grandes transformações não ocorreram, muitos policiais durante algumas conversas costumavam dizer que "só mudou o nome e aumentou o trabalho", tendo em vista que mesmo enquanto grupamento, o BEPE já tinha uma grande autonomia decisória a respeito de suas atividades internas e externas (mesmo que fosse uma companhia do Batalhão de Choque), além de já ter seu próprio espaço físico. Apesar das mudanças práticas serem poucas, burocraticamente, enquanto batalhão, as mudanças são significativas como maior possibilidade de conseguir recursos junto ao Governo Estadual e ao Comando Geral da PMERJ. Apesar de necessitar maior recurso humano para o aparato administrativo, hoje o BEPE é completamente independente e não necessita percorrer a longa distância de Deodoro até ao Batalhão de Choque que fica no Centro da cidade do Rio de Janeiro; trâmite que ficou complicado desde a mudança da sede do GEPE para o local atual. Foi uma das principais mudanças com a transformação em batalhão, pois o GEPE já contava com basicamente toda a estrutura de hoje.

Motivados pela lealdade a seus amigos, unidos pela paixão por um clube de futebol, aliados em nome de uma torcida, próximos pela vizinhança, os torcedores organizados reconhecem-se um no outro, sentem-se pertencentes a um grupo onde não são julgados, mas sim entendidos, assim, se veem encorajados e motivados o suficiente para lutar, literalmente, para proteger todo esse universo o qual ele acredita ter tanto valor. 


\section{Referências}

BAYLEY, David H. Padrões de Policiamento: Uma análise Internacional Comparativa (Polícia e Sociedade; n. 1). Tradução de Renê Alexandre Belmonte. 2. ed. 1. reimpr. São Paulo: Editora da Universidade de São Paulo, 2006.

BORGES, Fernando César. Esporte mais violento? - Possibilidades de análise através de Elias e Dunning. oㅡㄹ Encontro da ALESDE "Esportes na América Latina: atualidade e perspectivas". UFPR - Curitiba - PR, 2008

BOURDIEU, Pierre. A dominação masculina. Tradução de Maria Helena Kühner. 4 ed. Rio de Janeiro: Bertrand Brasil, 2005.

BRAGA, Jorge Luiz Medeiros. As torcidas Uniformizadas (Organizadas) de Futebol no Rio de Janeiro nos anos 1940. Revista Digital Esporte e Sociedade, Niterói, ano 5, n.14, mar.2010/jun.2010.

BRASIL. Lei n.10.671, de 15 de maio de 2003. Dispõe sobre o Estatuto de Defesa do Torcedor e dá outras providências. Disponível em: <http://www.planalto.gov.br/ccivil_03/Leis/2003/L1o.671.htm>. Acesso em: 05 de novembro de 2018.

CERQUEIRA, Carlos Magno Nazareth. O futuro de uma ilusão: o sonho de uma nova polícia. In: Vol. 6 de Coleção Polícia amanhã: Textos fundamentais de polícia. Universidade do Texas. Editora: Instituto Carioca de Criminologia, 2001.

ELIAS, Norbert. Cap. X: Mudanças na Agressividade. In: O Processo Civilizador: uma história dos costumes, vol. 1. Rio de Janeiro, Zahar, 2011, p. 189-202.

LAHUD GUEDES, Simoni. Que "povo brasileiro" no campo de futebol?. Razón y Palabra, núm. 69, julio-agosto, 2009, pp. 1-9 Universidad de los Hemisferios Quito, Ecuador

LEAL, Ana Beatriz; PEREIRA, Íbis; MUNTEAL FILHO, Oswaldo. Sonho de uma polícia cidadã: Coronel Carlos Magno Nazareth Cerqueira. Rio de Janeiro: NIBRAHC, 2010.

MICHAUD, Y. A violência. São Paulo: Ed. Ática, 1989.

MISSE, Michel. Crime, sujeito e sujeição criminal: aspectos de uma contribuição analítica sobre a categoria "bandido". Lua Nova, São Paulo, 79: 15-38, 2010. Disponível em: <http://www.scielo.br/pdf/ln/n79/ao3n79.pdf.>. Acesso em: 19 abr. 2021.

. Violência e Teoria Social. DILEMAS, Revista de Estudos de Conflito e Controle Social, v. 9, n. 1, jan./abr. 2016, p. 45-63. 
MUNIZ, J. Ser policial é, sobretudo, uma razão de ser - Cultura e cotidiano da Polícia Militar do Estado do Rio de Janeiro. 1999. 289 f. Tese (Doutorado em Ciência Política) - Instituto Universitário de Pesquisas do Rio de Janeiro, IUPERJ, Brasil. 1999

MUNIZ, Jacqueline de Oliveira; JUNIOR, Domício Proença. Mandato Policial. In: LIMA; RATTON; AZEVEDO (Orgs.). Crime, Polícia e Justiça no Brasil. (2014). São Paulo. Editora Contexto: p. 491-502.

PALHARES, Marcelo Fadori Soares et al. Lazer, agressividade e violência: considerações sobre o comportamento das torcidas organizadas. Motriz: rev. educ. fis., Rio Claro, v. 18, n. 1, p. 186-199, Mar. 2012. Disponível em: <http://www.scielo.br/scielo.php?script=sci_arttext\&pid=S198o-

65742012000100019\&lng=en\&nrm=iso $>$. Acesso em: 19 abr. 2021.

PIMENTA, Carlos Alberto Máximo. Violência entre torcidas organizadas de futebol. São Paulo Perspec. [online]. 200o, vol.14, n.2, p. 122-128.

PORTO, Maria Stela Grossi. Sociologia da Violência do Conceito às Representações Sociais. 1. ed. Brasília: Ed. Francis/Verbena, 2010. v. 1. 336 p.

SILVA, Robson Rodrigues da. Entre a caserna e a rua: o dilema do "pato": Uma análise antropológica da identidade policial militar, a partir da Academia de Polícia Militar D. João VI. Dissertação de Mestrado em Antropologia, UFF, 2009.

SIMÕES, I. Clientes versus rebeldes: novas culturas torcedoras nas arenas do futebol moderno. Rio de Janeiro: Multifoco, 2017.

SIMMEL, Georg. O conflito como sociação. RBSE-Revista Brasileira de Sociologia da Emoção, v. 10, n. 30, p. 569-574, 2011.

STORANI, Paulo. "Vitória Sobre A Morte: A Glória Prometida": O 'Rito De Passagem' $\mathrm{Na}$ Construção Da Identidade Dos Operações Especiais Do Bope. Dissertação apresentada ao Programa de Pós-Graduação em Antropologia da Universidade Federal Fluminense, como requisito parcial para obtenção do Grau de Mestre em Antropologia - UFF. 2008.

TEIXEIRA, Rosana da Câmara. Futebol, emoção e sociabilidade: narrativas de fundadores e lideranças dos movimentos populares de torcedores no Rio de Janeiro. Esporte e Sociedade, Futebol, Emoção e Sociabilidade. Ano 8, n 21, março de 2013.

TOLEDO, Luiz Henrique de. Lógicas no futebol: dimensões simbólicas de um esporte nacional. 200o.Universidade de São Paulo, São Paulo, 2000.

Anpocs.

1996. Torcidas Organizadas de Futebol. Campinas: Autores Associados e 
ZALUAR, Alba. Etos Guerreiro e Criminalidade Violenta. In: Renato Sergio de Lima; José Luiz Ratton; Rodrigo G. de Azevedo. (Org.). Crime, Polícia e Justiça no Brasil. 1.ed.São Paulo: Editora Contexto, 2014, v. 1, p. 35-5o.

Um debate disperso: violência e crime no Brasil da redemocratização. São Paulo Perspec., São Paulo, v.13, n.3, p.3-17, Sept. 1999. Disponível em: $<$ http://www.scielo.br/scielo.php?script=sci_arttext\&pid=So102-

$88391999000300002 \& \operatorname{lng}=e n \& n r m=i s o>$. Acesso em: 11 de jan. de 2020 